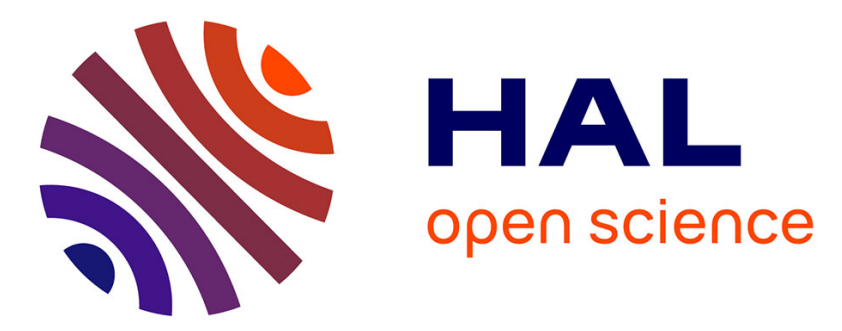

\title{
Proteasome Activity Deregulation in LEC Rat Hepatitis: Following the Insights of Transcriptomic Analysis
}

\author{
Adriana Márquez-Quiñones, Alain Paris, Balbine Roussel, Julio \\ Perez-Carreon, Jean Marie François, Véronique Le Berre, Saul Villa-Trevino, \\ Françoise Guéraud
}

\section{To cite this version:}

Adriana Márquez-Quiñones, Alain Paris, Balbine Roussel, Julio Perez-Carreon, Jean Marie François, et al.. Proteasome Activity Deregulation in LEC Rat Hepatitis: Following the Insights of Transcriptomic Analysis. OMICS, 2007, 11 (4), pp.367 - 384. 10.1089/omi.2007.0039 . hal-01849378

\section{HAL Id: hal-01849378 \\ https://hal.science/hal-01849378}

Submitted on 5 Jun 2019

HAL is a multi-disciplinary open access archive for the deposit and dissemination of scientific research documents, whether they are published or not. The documents may come from teaching and research institutions in France or abroad, or from public or private research centers.
L'archive ouverte pluridisciplinaire HAL, est destinée au dépôt et à la diffusion de documents scientifiques de niveau recherche, publiés ou non, émanant des établissements d'enseignement et de recherche français ou étrangers, des laboratoires publics ou privés. 
Proteasome activity deregulation in LEC rat hepatitis: following the insights of transcriptomic analysis.

Adriana MARQUEZ-QUIÑNONES ${ }^{1,2}$, Alain PARIS $^{1}$, Balbine ROUSSEL ${ }^{1}$, Julio PEREZ-CARREON ${ }^{1}$, Jean-Marie FRANÇOIS ${ }^{3}$, Véronique Le BERRE ${ }^{3}$, Saúl VILLATREVIÑO ${ }^{2}$, and Françoise GUÉRAUD ${ }^{1}$.

1. INRA, UMR 1089-Xenobiotiques, F-31000, Toulouse, France.

2. Departamento de Biología Celular, Centro de Investigación y de Estudios Avanzados del IPN, México, DF, MEXICO

3. UMR5504, UMR792 Ingénierie des Systèmes Biologiques et des Procédés, CNRS, INRA, INSA, F-31400 Toulouse

Running Head: DNA Microarray analysis of LEC rat hepatitis development Corresponding Author:

Françoise Guéraud Ph.D

Institut National de la Recherche Agronomique

UMR 1089-Xenobiotiques, INRA/ENVT

180, Chemin de Tournefeuille, BP 3

31931, Toulouse Cedex 9

France

Tel : (33) 561-38-5383

Fax : (33) 561-38-52-44

E-mail: fgueraud@toulouse.inra.fr 


\section{Abstract}

LEC rats have a mutation in a gene related to hepatic copper excretion, the Atp $7 b$ gene. As a consequence, this rat strain shows an abnormal copper accumulation in the liver. The copper accumulation accelerates reactive oxygen species (ROS) production. This is believed to be the origin of the acute hepatitis and the subsequent hepatocellular carcinoma that spontaneously develop in these rats. Here we present a DNA microarray analysis of LEC rats in liver at different stages of hepatitis compared to a seemingly control obtained in D-penicillamine-treated LEC rats. Multivariate statistical analyses as Partial Least Square (PLS) regression between transcriptomic data and hepatitis markers in plasma led us to select genes related to hepatitis development. After PLSDiscriminant Analysis (PLS-DA), 239 genes important for the separation between the different rat groups were selected. Gene ontology classification of selected genes showed a deregulation in protein metabolism-related genes. Genes from proteasome pathway were up-regulated; however, trypsin-like and peptidylglutamyl peptide hydrolase $20 \mathrm{~S}$ proteasome activities were diminished during hepatitis. One mechanism of proteasome inactivation is oxidative stress. Hence, we propose a deregulation of proteasome genes as a result of oxidative inactivation of proteasome activity during hepatitis in LEC rats. Our results add to the known oxidative stress and inflammation characterization of the hepatitis process, leading to new insight concerning hepatitis and hepatocarcinogenesis development.

Keywords: oligonucleotides microarrays, LEC rats, hepatitis, PLS-2 regression, PLSDA, oxidative stress. 


\section{Introduction}

In humans, chronic liver diseases are generated by different causes. Chronic alcohol consumption, viral infections, metabolic dysfunctions, xenobiotic exposition and metal overload are factors associated with hepatitis and liver tumor development. Oxidative stress seems to be a common mechanism of hepatitis development between all these different causes . Patients suffering from hepatitis $\mathrm{C}$ manifest hepatic oxidative stress, condition that is exacerbated by alcohol consumption . 8-nitroguanine, a marker of DNA oxidation, is highly formed in patients with hepatitis C. Furthermore, some hepatitis $\mathrm{C}$ virus (HCV) carriers with normal alanine aminotransferase (ALT) levels in serum have elevated levels of lipid peroxidation products and low levels of GSH in plasma. In these patients, a greater degree of oxidative stress markers correlates with a more severe status of the disease. In Wilson's disease, mutations of the copper transporting ATPase ATP7B gene lead to decreased biliary copper excretion and accumulation of copper in liver. Copper is known to induce reactive oxygen species (ROS) production. Oxidative stress resulting from an increased production of free radicals via the copper accumulation and defects in antioxidant defenses is highly relevant to the toxic process in Wilson's disease .

During oxidative stress, ROS can interact with biomolecules such as DNA, RNA, proteins and lipids, leading to their oxidation and as a consequence to cellular damage, genomic instability, apoptosis and cell cycle alterations . Nevertheless, the evidence of the importance of oxidative stress during liver pathologies, mechanisms in which ROS can lead to hepatitis development, are not fully understood. The aim of this study is to evaluate the evolution of gene expression regarding hepatitis and its association with oxidative stress. In this context, LEC rats has been described as a good model for 
studying the relation between oxidative stress, hepatitis and heptatocarcinogenesis . LEC rats suffer from a spontaneous copper accumulation due to a deletion in the gene responsible for liver copper excretion, the Atp 7 gene . As a consequence, LEC rats suffer from an acute hepatitis followed by a period of chronic hepatitis and ultimately liver tumor development . Liver pathology progression in LEC rat model is the same as the one seen in human Wilson's disease. Moreover, LEC rat model is considered as the biological model for studying this liver pathology .

Nowadays, transcriptomic technology is highly used to define the repertoire of genes that are differentially expressed by cells or tissues exposed to different stimuli like xenobiotic exposition or disease development. One of the challenges in DNA microarray analysis is data treatment and interpretation of the great amounts of information in a biological context. In this regard, multivariate statistical analyses are interesting tools for the selection of genes with highlighted biological meaning in the explanation of the model. Here we present a DNA microarray analysis of the development of hepatitis in LEC rats. Partial Least Square (PLS) regression and PLSDiscriminant Analysis (PLS-DA) led us to the selection of genes that discriminated between LEC rats at different hepatitis stages.

\section{Material and methods}

\section{Animals and treatment}

Long Evans Cinnamon-like (LEC) rats were bred in our Institution animal facility from rats given by Tokushima University (Japan). Male LEC rats were maintained in metabolic cages from 6 weeks old until sacrifice. Experiments were done under Institutional Animal Care and Use Committee Guidelines. Rat groups $(n=6)$ were 
classified according to hepatitis stage, age and treatment (Table 1). Liver disease stage was assigned according to aspartate aminotransferase (AST), alanine aminotransferase (ALT) activities and total bilirubin (t-bil) levels in plasma and from histopathology of the liver. For D-penicillamine-treated rats group, D-penicillamine was administered in drinking water (100 mg/kg/day) for 6 weeks. D-penicillamine (Sigma, Saint Quentin Fallavier, France) concentration was adjusted according to rats water consumption.

\section{Lipid peroxidation quantification}

Urine samples were collected daily from rats housed in plastic metabolic cages. $0.5 \mathrm{ml}$ of a $360 \mathrm{mM}$ butylhydroxytoluene (BHT) ethanolic solution was added to the urine collection tubes that were placed in a unit maintained at $0{ }^{\circ} \mathrm{C}$ during urine collection. 24 $\mathrm{h}$ collected urine samples were stored at $-20^{\circ} \mathrm{C}$ until analysis.

8-Isoprostane (8-IsoPGF $2 \alpha)$ is considered as a good marker of inflammation and oxidative stress. Urine 8 -IsoPGF $2 \alpha$ was quantified by competitive enzyme immunoassay as described elsewhere . 8-isoprostane EIA antiserum, 8-isoprostane EIA standard and 8-isoprostane $\mathrm{AChE}$ tracer were obtained from Cayman (SPI-BIO, Montigny-le-Bretonneux, France).

\section{Tissue preparation}

Rats were sacrificed by exsanguination under ether anesthesia. Blood was taken from the aorta vein for plasma separation. Liver was excised, washed in physiological saline solution. For RNA isolation, liver samples were immersed in RNAlater (Qiagen, Courtaboeuf, France) following manufacturer's instructions and stored at $-80{ }^{\circ} \mathrm{C}$. For light microscopy examination, liver samples were fixed in $4 \%$ buffered formaldehyde, embedded in paraffin and sections were stained with hematoxylin and eosin. For cytosol 
extraction, $10 \%(\mathrm{w} / \mathrm{v})$ liver homogenates were prepared in $50 \mathrm{mM}$ Tris- $\mathrm{HCl} \mathrm{pH} 8.0$ containing $0.1 \mathrm{mM}$ EDTA, $1 \mathrm{mM} \beta$-mercaptoethanol. Homogenates were centrifuged at $100,000 \mathrm{~g}$ for $1 \mathrm{~h}$ at $4{ }^{\circ} \mathrm{C}$; supernatants were stored at $-80{ }^{\circ} \mathrm{C}$ until use.

\section{RNA extraction}

Total RNA from RNAlater-stabilized liver samples were performed following the instructions from Qiagen RNeasy mini kit using the On-Column DNase digestion set (Qiagen). Quality and quantity were determined by capillary electrophoresis on the bioanalyzer / Agilent (RNA 6000 Nano Assay) and Nanodrop / Nyxor Biotech. Only samples with $\lambda(260 \mathrm{~nm} / 280 \mathrm{~nm})>1.9$ and rRNA cela est obtenu avec le nanodrop et pas le bioanalyzer $(28 \mathrm{~S} / 18 \mathrm{~S})>1.7$ ratios were taken for DNA microarray and quantitative RT-PCR assays.

\section{Quantitative RT-PCR (qRT-PCR)}

$2 \mu \mathrm{g}$ of total RNA was reverse transcribed using SuperScript II-reverse transcriptase system (Invitrogen, Cergy Pontoise, France) following manufacturer's instructions. Quantitative PCR assay for cDNA was carried out using TaqMan Universal PCR master mix in a AB PRISM 7000 sequence detection system (Applied Biosystem, Courtaboeuf, France). Fluorescent probes for rat glutathione S-transferase pi (GSTP) gene, probe code: Rn00821792_g1 were used. Data were normalized against beta actin gene expression, probe Rn00667869-m1 (Applied Biosystem). Signals were quantified using a standard curve made by serial dilutions of a cDNA pool from all samples.

\section{Proteasome peptidase activities}


Chymotrypsin-like (ChT), trypsin-like (TL) and peptidylglutamyl peptide hydrolase $(\mathrm{PGPH})$ proteasome activities were determined with fluorogenic synthetic peptides $\mathrm{N}$ Succinyl-Leu-Leu-Val-Tyr-7-amido-4-methylcoumarin (LLVY-AMC), BOC-Leu-SerThr-Arg-7-amido-4-methylcoumarin $\quad$ (BOC-AMC) and Z-Leu-Leu-Glu- $\beta$ naphthylamide (Z-LLG-NA), respectively. Assays were performed as described elsewhere . Briefly, cytosolic fractions containing $150 \mu \mathrm{g}$ of protein were incubated with fluorogenic substrates $(50 \mathrm{mM})$ and SDS $0.06 \%$ in $150 \mathrm{mM}$ Tris- $\mathrm{HCl} \mathrm{pH} 8.0$ for 30 minutes at $37^{\circ} \mathrm{C}$. The reaction was stopped by adding $1 \mathrm{ml}$ SDS $1 \%$ and $2 \mathrm{ml} 0.1 \mathrm{M}$ sodium borate $\mathrm{pH}$ 9.1. The peptidase activity was determined fluorometrically by measuring the release of 7-amino-4-methylcoumarin $\left(\lambda_{\mathrm{exc}}=370 \mathrm{~nm}, \lambda_{\mathrm{em}}=430 \mathrm{~nm}\right)$ and 2-naphthylamine $\left(\lambda_{\text {exc }}=323 \mathrm{~nm}, \lambda_{\mathrm{em}}=400 \mathrm{~nm}\right)$ in a Jobin Yvon spectrofluo JY3D fluorometer (Moriba Jobin Yucn, Long jameceu, France. A standard curve of fluorescence for 7-amino-4-methylcoumarine and 2-naphthylamine was used to calculate the concentration of liberated products in the assay.

\section{SDS-PAGE and immunoblotting}

Cytosolic protein fractions were separated by SDS-PAGE using a mini-PROTEAN II electrophoresis cell (Bio-Rad, Marnes-la-Coquette, France). Following transfer, the nitrocellulose membranes were probed with antibodies to proteasome C2 subunit, PROS-30 (Santa Cruz Biotechnology, Inc., Tebu-bio, Le Perray en Yvelines, France), or $\alpha$-Tubulin (Sigma), and visualized using the ECL chemiluminescent system (Amersham Biosciences, Orgay, France, c'est Amersham ou GE?).

\section{Microarray analysis}


Il faudrait peut être faire un petit paragraphe sur les lames elles mêmes. Lames avec des oligo 70 mers provenant du probes set de chez opéron et spotté sur des UltraGap de chez corning

\section{Preparation of labeled cDNA}

Total RNA $(5 \mu \mathrm{g})$ was used for cDNA preparation. Reverse transcription was made using ChipShot ${ }^{\mathrm{TM}}$ reverse transcriptase from Promega (Promega, Charbonnieres Les Bains, France), using $\mathrm{Cy} 3-$ and $\mathrm{Cy} 5-\mathrm{dCTP}$ from Amersham Bioscience. cDNA purification was made by Promega ChipShotTM labeling Clean-up System. Dye incorporation was checked by measuring the absorbance at 260 and $550 \mathrm{~nm}$ for $\mathrm{Cy} 3$ and 260 and $650 \mathrm{~nm}$ for Cy5 with the Nanodrop /Nyxor Biotech.

\section{Array hybridization and scanning}

Equal amounts of $\mathrm{Cy} 3-$ and Cy5-labeled cDNA from control and tested groups were hybridized for 8 hours at $42^{\circ} \mathrm{C}$ in the automatic Hybridization Machine Discovery from Ventana (Ventana Medical Systems, Illkirch, France). After hybridization, slides were washed twice in $2 \mathrm{X}$ sodium saline citrate (Ribowash buffer, Ventana Medical Systems) for 5 minutes with agitation and then once with $0.1 \mathrm{x}$ SSC buffer $(15 \mathrm{mM} \mathrm{NaCl}, 1.5 \mathrm{mM}$ sodium citrate, $\mathrm{pH}$ 7.0). Then dried by centrifugation. Slides were scanned with Axon 4000A Microarray Scanner (Molecular Devices, Saint Orégoire, France).

\section{Data analysis and public access}

All data reported here are available to public, via NCBI-GEO platform, as both original and normalized data. Image analysis was made by Genepix Pro V6 software. Each spot was evaluated and selected to be analyzed by Bioplot software (http://biopuces.insa- 


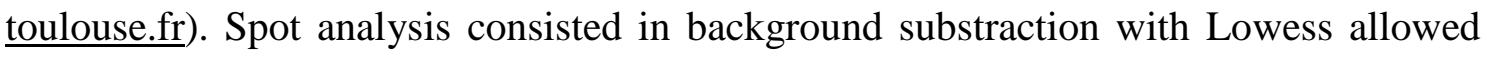
value 10, log transformation and Lowess normalization. The generated data set has been submitted to the National Center for Biotechnology Information (NCBI) Gene Expression Omnibus (GEO, http://www.ncbi.nlm.nih.gov/projects/geo/) database (GSE7654).

Data analysis consisted of a variance analysis. The whole data set (27004 gene probes) was subjected of an ANOVA using SPLUS 2000 software (MathSoft,inc., Seattle, WA). Significance was set as P-value $<0.05$. Partial Least Square (PLS)-2, PLS-Discriminant Analysis (PLS-DA) and orthogonal signal correction (OSC) was made using SIMCA-P 8.0 software (Umetrics, Umeg, Sweden). 239 Selected genes are enlisted in Table A as supplementary data.

For biological organization of data, gene ontology (GO) classification was performed by Gene Ontology Tree Machine from Vanderbilt University (http://bioinfo.vandrbilt.edu/gotm) .

\section{Statistical Analyses}

Multivariate statistical analyses are described above. Univariate statistical analysis for data from qRT-PCR, proteasome activities and immunoblotting are expressed as means \pm SD. Statistical differences were determined by ANOVA, followed by Bonferroni's post-hoc test.

\section{Results}

\section{Group classification:}

Table 1 (ne faut il pas mettre la légende des tableaux avec celles des figures?) contains the group classification according to rat disease state, age and treatment. Rats were 
classified into 5 groups; groups Normal $6 w$ and Normal $9 w$ correspond to non diseased young rats (6 and 9 weeks old respectively) that show low level of liver enzymes ALT, AST(comment est ce mesuré, je ne le trouve pas dans le materiel et methode?) in plasma and a normal liver architecture. Slight jaundice and Jaundice groups are non treated rats at different hepatitis stages. Both groups showed increased levels of hepatitis markers (ALT, AST and t-bil) in plasma, together with abnormal liver histology as necrosis, apoptosis and nuclear polymorphism, and an increase in lipid peroxidation as measured by urinary excretion of 8 -isoPGF2 $\alpha$. D-penicillamine, a copper chelator agent, is known to inhibit hepatitis development and oxidative stress in LEC rats. D-penicillamine-treated rats showed low liver enzymes in plasma, normal liver histology and low levels of urinary 8-isoPGF2 $\alpha$. As these rats behaved as normal rats, they were taken as control group for further experiments, and all the microarray comparisons were made against these rats.

\section{Microarray analysis and validation}

27004 oligo probes tested by pangenomic microarray analysis were filtered by ANOVA analysis. 696 probes with a $\mathrm{P}$ value $<0.05$ were considered as significant variables. In order to discriminate between genes related to hepatitis progression and those related to rat groups age difference, a PLS-2 regression between the 696 statistically significant genes and plasma hepatitis markers ALT, AST and t-bil was performed (Figure 1-A). PLS-2 regression showed a projection in which diseased rat groups, Slight Jaundice and Jaundice, were well separated from non diseased rat groups, Normal $6 \mathrm{w}$ and Normal $9 w$. However, these two latter groups could not be separated between each other by this analysis. The 696 genes were hence analyzed by a Partial Least Squares-Discriminant Analysis (PLS-DA) in order to sharpen the separation between all groups of rats (Figure 
1-B). PLS-DA, a supervised multidimentional statistical method, uses Principal Component Analysis (PCA) principles, i.e. data projection into different dimensions, to find those components which explain better the group differences. As shown in Figure 1-B, the first component [t1] projects a trajectory which defines the disease progression from normal non diseased rats (Normal 6w and Normal 9w groups) to strong diseased rats (Jaundice group) going through the slight diseased group (Slight jaundice).

The genes that contribute to axis building were defined using the Variable Importance Projection (VIP) criterion given by the SIMCA-P 8.0 software. From the 696 tested genes, 239 were considered as important for axis projection with a VIP $>0.8$. Table A (supplemental table) lists these 239 genes ordered by decreasing importance VIP value. Among the genes considered important for discrimination between tested groups, we found GSTP gene. GSTP is considered a tumor marker known to be expressed in LEC rats during hepatitis . Microarray data for GSTP expression was confirmed by qRT-PCR (Figure 2). In both techniques higher mRNA of GSTP levels during hepatitis were found, thereby validating the results obtained from pangenomic microarrays.

\section{Functional classification of VIP genes}

In order to achieve an objective interpretation of data, the 239 VIP variables were subjected to a functional classification based on Gene Ontology annotation (GO). This kind of classification allows us to focus on gene activities deregulated in the different groups. Currently, the $40 \%$ of total rat genome has a gene ontology annotation. For the 239 selected oligos 59 genes were shown to have a GO annotation in Biological Process ontology (Figure 3). From these genes, 38 fall into Metabolism, 19 in Organismal Physiological process and 19 in Regulation of physiological process categories which means 33.0, 16.5 and 16.5 percent of total genes falling in Biological Process ontology. 
Since Cellular Metabolism was the most deregulated gene function, we focused on this category. A sub-classification into a more specific gene function is shown in Figure 4. The most deregulated activities correspond to Protein Metabolism, and Nucleobase, Nucleoside, Nucleotide and Nucleic acid Metabolism with 18 (24.0\%) and 7 (9.3\%) genes, respectively. Tables 2 and 3 display the description and ratio of each gene falling into these two categories.

Interestingly, the one category with the highest amount of annotated genes belongs to the Protein Metabolism category. Furthermore, among the genes classified in this category, there was an increase in transcription levels of genes related to protein degradation by proteasome (Table 2).

\section{Proteasome activity}

The main function of the proteasome is to degrade unneeded or damaged proteins by proteolysis. cDNA Microarray data suggested that proteasome activity would be augmented since gene expression is augmented in diseased groups. In order to investigate this possibility, we determined the peptidase activities of $20 \mathrm{~S}$ proteasome using specific fluorogenic peptides as substrates in cytosolic fractions (Figure 5).

Our data showed that while there was no significant modification in chymotrypsin-like (ChT) proteasome activity, there was a considerable decrease in trypsin-like (TL) proteasome activity in diseased rat groups (Slight jaundice and Jaundice) but not in normal rat groups (Normal 6w and Normal 9w) je ne suis pas vraiment convaincue par normal 6w qui est lui aussi assez bas) as compared to the control group D-penicillamine $\left(F_{4,25}=58.62, P<0.0001\right)$ (Figure $5 \mathrm{~A}$ and B). Similarly to TL activity, the peptidylglutamyl peptide hydrolase (PGPH) proteasome activity diminished in Slight 
Jaundice group (Figure 5-C). Nevertheless, in Jaundice rat group the PGPH proteasome activity was restored $\left(F_{4,25}=13.01, P=0.0075\right)$.

In order to evaluate whether changes in proteasome activities were due to variations in proteasome protein levels, a Western Blot was made. As shown in Figure 6, proteasome C2 subunit protein levels, a protein used to measure the levels of the 20S proteasome, increased significantly in diseased groups compared to control D-penicillamine group $\left(F_{4,25}=10.86, P=0.015\right)$. Thus, diminishing in TL and PGPH proteasome activities does not correspond to a decrease in $20 \mathrm{~S}$ proteasome levels but to an inhibition of the protein activity . (effectivement c'est mieux d'avoir rajouté cette phrase)

\section{Discussion}

Oxidative stress has been widely associated with hepatitis and hepatocarcinogenesis. The LEC rat model is a useful tool for studying the oxidative stress-related hepatitis and hepatocarcinogenesis process. Two major characteristics are considered in LEC rat model. First, the progression from hepatitis to hepatocarcinogenesis seems to mimic what is seen in human Wilson's disease, in which chronic inflammation, fibrosis and cirrhosis are involved. The second characteristic is the fact that hepatitis and hepatocarcinogenesis can be modulated by copper chelator agents, like D-penicillamine, and by changes in diet composition. This makes this model an interesting tool to evaluate the impact of different drugs and therapies in hepatitis development . Furthermore, modulating hepatitis development, we are able to study the mechanism involved in hepatitis and hepatocarcinogenesis generation.

A first evaluation of gene expression in LEC rats was made by Klein et al. in 2003 . Authors compare the difference in gene expression patterns between female LEC rats at different hepatitis stages and against Long Evans agouti (LEA) rats as control. LEA rats 
are widely used as control rats in LEC rat studies. However LEA rat genetic background might not be the same as the one of LEC rats. Both LEA and LEC rat strains derive from a close colony of Long Evans rats. Despite this common genetic origin, differences in enzyme activity and content between LEC and LEA rats have been reported . From their transcriptomic assay authors found, as expected, deregulation in genes related to oxidative stress and inflammation. However, the data analysis was focused only on the description of the most highly deregulated genes as the genes that would explain hepatitis progression. Even if strong changes in the expression level of a single gene may be important for changing cell functions, minor fluctuations in gene expression could have major consequences. Furthermore, most important activities are usually not the result of a single molecule, but depend on the coordinated effects of multiple molecules . In our study, in order to get a more global analysis of microarray data, results were submitted to multivariate statistical analyses, coupled to a biological interpretation based on gene family function as determined by GO classification.

Rat groups were defined by their liver hepatitis stage as interpreted by the plasma levels of the known hepatitis markers ALT, AST, t-bil and from liver histological observations. Oxidative stress increased as hepatitis developed as seen by high levels of urinary 8-IsoPGF $2 \alpha$, a known marker of lipid peroxidation, confirming that copperinduced oxidative stress might be the cause of hepatitis and hepatocarcinogenesis in LEC rats. D-penicillamine is a copper chelator agent that is well known to inhibit initiation and progression of hepatitis as well as oxidative stress in LEC rats . Dpenicillamine-treated LEC rats behaved as healthy rats compared to age matched nontreated LEC rats. Indeed, clinical features of D-penicillamine-treated rats, low levels of ALT and AST activities in plasma, normal liver architecture and lower lipoperoxidation products levels in urine show that these rats behave as normal rats. They would have a 
similar genetic background as non-treated rats making this rat group a suitable control group for gene expression changes comparison. In order to evaluate the effect of Dpenicillamine in gene expression, Long Evans rats were treated with D-penicillamine in a similar way as in D-penicillamine LEC group. Gene expression was compared to untreated Long Evans rats. No significant difference between those two groups was found (data not shown).

Changes in gene expression might be due to hepatitis development but also to age difference between groups. In order to select those genes that are related to hepatitis development, a PLS-2 analysis between microarray and plasma hepatitis markers data was made. PLS regression is a recent technique that generalizes and combines features from principal component analysis (PCA) and multiple regression. Its goal is to predict or analyze a set of dependent variables (matix Y, i.e. plasma hepatitis markers) from a set of independent variables (matrix X, i.e. microarray data) or predictors . With this kind of analysis we were able to show a projection of group of animals regarding hepatitis with a good discrimination between non-diseased and diseased animals. However, this regression was not enough powerful to discriminate the two non-diseased groups (Normal 6w and Normal 9w), maybe because the number of hepatitis markers is much reduced and their values are very similar between these groups. To solve this problem and in order to simplify the information obtained from PLS-2 regression, a PLS-DA was made. PLS-DA takes the advantage of prior class information to attempt to maximize the separation between groups of observations. In PLS-DA, a matrix made by classifying the observations is considered as the dependent variable (Y) and hence, the set of independent variables (X, i.e. microarray data) are tested to better predict the maximal separation between groups. More than 50\% of VIP-positive oligos from PLS- 
DA were common to those coming from PLS-2 regression demonstrating that PLS-DA group separation is well correlated to animal hepatitis development.

Statistical VIP criterion is a measure which quantifies the influence on the response (on the latent variable describing the projection of hepatitis development) of each variable summed over all components and categorical responses relative to the total sum of squares of the model. It is a useful tool to select specific set of genes that distinguishes animals at different stages of hepatitis, making it an important parameter to find possible metabolic pathways involved in disease development. Among the genes found with a high VIP value, GSTP gene was present. GSTP expression increasing has been described during hepatitis in LEC rats . qRT-PCR of GSTP gene validates microarray findings and gene selection by VIP criterion. Furthermore, GSTP is considered as one of the most reliable tumor markers in liver, and its expression during hepatitis might be related to the development of preneoplastic and neoplastic liver lesions seen in this rat strain .

During hepatitis progression in LEC rats, a strong oxidative stress takes place. Oxidation of biomolecules as DNA, lipids and proteins has been extensively described [for review see ]. According to these observations, our analyses of microarray data show Protein Metabolism and Nucleobase, Nucleoside, Nucleotide and Nucleic acid metabolism deregulation as established by GO classification. Ontologies are built from a structured, controlled vocabulary . The aim of ontology classification is to help biologists to make a global interpretation of transcriptomic data in a whole context by associating genes to the biological function of their products. Knowledge about gene function is a large and growing information that is updated frequently by the Gene Ontology Consortium . In the case of rat genome, currently $40 \%$ of genes have a GO annotation . Even with this lack of information, GO classification is a good tool for a 
global analysis of gene perturbations and results can be further updated for GO annotations by submitting them to web database as Rat Genome Database (http://rgd.mcw.edu/) or Gene Ontology Consortium site (http://www.geneontology.org/).

According to genes involved in nucleobase, nucleoside, nucleotide and nucleic acid metabolism, genes involved in DNA reparation are up-regulated in Jaundice group. Growth Arrest and DNA Damage 45-alpha (GADD45-alpha) is a nuclear protein involved in the maintenance of genomic stability, DNA repair, and suppression of cell growth. Overexpression of GADD45 gene has been reported in LEC rats at early stages of hepatitis suggesting important DNA damage. The mechanisms by which oxidized DNA bases are repaired include the base excision repair (BER) pathway. M1G, ethenoDNA adducts, 8-hydroxyguanine and other oxidized base lesions are removed by this pathway . Acute hepatitis in LEC rats impairs the repair of oxidative DNA base damage by altering the activity of DNA glycosylases, endonuclease II and 8-oxoguanine DNAglycosylase which initiate the BER pathway . Interestingly, our results show overexpression of DNA-repair protein XRCC1 gene. XRCC1 protein seems to play a central role in coordinating the enzymes participating in BER pathway . XRCC1 protein interacts with all enzymes of BER downstream of DNA-glycosylase leading to the stabilization of the corresponding enzyme. Hence, up-regulation of XRCC1 in LEC diseased groups may contribute to BER pathway recovery in LEC rats. Further investigations are needed to determine the role of XRCC1 in BER pathway in LEC rats. Protein Metabolism was the one category with the highest amount of associated genes. The results suggest an increase in protein degradation, since genes falling in this category are genes related to proteasome system and to other peptidases. Increase in protein degradation could reflect protein damage as protein oxidation. One of the 
mechanism in which oxidized proteins are degraded involves the proteasome system. It has been demonstrated that mild oxidation increases protein degradation by increasing protein susceptibility to recognition and degradation by the proteasome. According to microarray data, proteasome-associated genes such as Psmb5, Psma6, Psmd12 and Psmd6 were up-regulated. Moreover, oxidative stress and protein oxidation have been described in LEC rats . Together these results suggest that proteasome activity should be augmented in Slight jaundice and Jaundice groups. However, TL and PGPH 20S proteasome peptidase activities were diminished in these groups. Protein levels of proteasome C2 subunit were significantly increased in Slight jaundice and Jaundice groups compared to D-penicillamine group. This suggests that that diminution of proteasome activities may not be due to less proteasome protein levels in cell, but because a direct inhibition in protein activity.

If oxidized proteins are not eliminated through proteasome pathway, they are able to accumulate and to aggregate . Oxidized protein aggregates are very difficult to eliminate because they can not be unfolded, an important step in protein degradation, and they are able to cross-link with proteasome subunits enhancing proteasome inhibition. 4hydroxy-2-nonenal (HNE), a major end product of lipid peroxidation, modifies proteins leading to the formation of such protein aggregates . Furthermore, HNE can inhibit directly the proteasome activity by covalent binding to proteasome subunits. Okada et al. Date have found similar results for the inhibition of TL and PGPH peptidase activities under oxidative stress conditions in kidney. Authors concluded that HNEproteasome adduction was partially responsible for the proteasome inhibition under oxidative stress conditions . These findings lead us to propose, for the first time, the inhibition of proteasome activities by oxidative stress during hepatitis progression in LEC rats. 
Inhibition of proteasome activities may induce the expression of proteasome genes in a feedback mechanism that would allow the compensation of reduced protein degradation. Meiners et al. , have studied the expression of proteasome genes after the inhibition of ChT proteasome peptidase activity by specific proteasome inhibitors. They showed that there is a concerted expression of almost all the $20 \mathrm{~S}$ proteasome subunits following proteasome activity inhibition. Our results show that from the three subunits that have peptidase activity, only the gene corresponding to the $\beta 5$ subunit (Pmsb5 gene) is overexpressed during hepatitis (table 2). 35 subunit is responsible for ChT proteasome activity, which is not modified during hepatitis (figure 5-A). Hence, the upregulation of $\beta 5$ subunit may compensate for the proteasome ChT activity inhibition. The $\beta 5$ active site is the archaetypical and most crucial activity for proteasome maturation and proteolysis . Cells overexpressing $\beta 5$ subunit have increased survival rates and a better response under oxidative stress conditions . Thus, it seems that $\beta 5$ subunit expression might compensate at least partially for the proteasome inhibition during oxidative stress.

The proteasome is an essential organelle that participates in different cellular functions, like apoptosis, survival and DNA reparation . Alterations in proteasome activity have been related to different pathologies including Parkinson and Alzheimer diseases, ageing and metabolic perturbations . Oxidized and damaged proteins and their accumulation may alter cellular functions giving rise to deleterious effects on cellular homeostasis that could be involved in initiation and progression of carcinogenesis .

In conclusion, our work presents for the first time a global analysis of microarray data for liver transcriptome that brings us to the study of new insights in hepatitis development and in cellular response to oxidative damage. In this study, multivariate statistical analysis coupled to a biological interpretation of microarray data allowed us 
to focus on proteasome system and on the consequences of proteasome inhibition as a main deregulated pathway that might be important in oxidative stress-induced hepatitis. Our work shows an original and functional way of microarray data analysis that helps researchers to propose some new hypotheses in a more global manner, taking into account not only the genes with largest deregulation, but also groups of genes that really participate in animal groups discrimination. 


\section{Acknowledgments}

We sincerely thank Florance Blas y Estrada and Raymond Gazel for technical assistance and animal care.

\section{Grants}

This work was supported by the Programme Alßan, the European Union Programme of High Level Scholarships for Latin America, scholarship No. E04D035320MX, ECOSANUIES grant M02-S01, CONACYT grant 39525-M and a fellowship from CONACYT AMQ165505. 
References 


\section{Figue legends}

Figure 1. Relation between hepatitis progression and gene expression. 696 statistically significantly variables from transcriptomic data $(\mathrm{P}<0.05)$ were used for a PLS-2 regression against plasma hepatitis markers, ALT, AST and t-bil (A). (B) PLSDA of transcriptomic data Boxes: Normal 6w. Triangles: Normal 9w. Crosses: Slight jaundice. Dots: Jaundice.

Attention dans la figure la légende n'est pas très nette. Peux tu améliorer ceci?

Figure 2. Confirmation of the differential expression of GSTP by quantitative RTPCR. Triangles: GSTP expression units from microarray data. Open circles: GSTP expression unites from TaqMan QRTPCR assay. Data is expressed as ratio Test/Control means $\pm \mathrm{SD}$ where control is D-penicillamine-treated rat group.

Figure 3. Gene ontology classification for 59 known genes. Classification by biological process was made (1-10). Chart data are read as: Category name (Accession): number of tested genes annotated in this category, Percent of tested genes annotated in this category against total tested genes having a GO annotation.

Figure 4. Metabolism ontology sub-classification. Genes being part of metabolism classification were sub-classified according to their specific activity (1-25). Chart data are read as: Category name (Accession): number of tested genes annotated in this category, Percent of tested genes annotated in this category against total tested genes having a GO annotation. 
Figure 5. Changes in proteasome activities in the liver of LEC rats at different disease stages. The proteasome activities in the liver of LEC rats in different groups were measured using the fluoropeptides, s-LLVY-AMC for the ChL activity (A), BocLSTR-AMC for the TL activity (B), and Z-LLE- $\beta N A$ for the PGPH activity (C), as proteolytic substrates. Each determination was performed at least in triplicate. Values refer to proteasome activity means $\pm \mathrm{SD}$. $\mathbf{a}$ is significantly differently from $\mathbf{b}$ and $\mathbf{c}$ as determined by ANOVA and the Bonferroni post-hoc test.

Figure 6. Immunodetection of proteasome in liver of LEC rats at different disease stage and treatment. A, representative image of immunoblot analysis for proteasome C2 subunit and alpha-Tubulin proteins. B, densitometry analysis of immunoblot assay, values refer to proteasome/alpha-tubulin ratio means $\pm \mathrm{SD}(\mathrm{n}=6)$. a is statically differently from $\mathbf{b}$ and $\mathbf{c}$ as determined by ANOVA and the Bonferroni post-hoc test.

Dans les tables pourquoi as tu enlevé la collone avec les FDR? 
Table 1. Group classification. Rats were classified according to their disease state, age and treatment. Values refer MEANS (SD= Standard Desviation). $\mathbf{a}$ is statically differently from $\mathbf{b}$ and $\mathbf{c}$ as determined by ANOVA and the Bonferroni post-hoc test.

\begin{tabular}{|c|c|c|c|c|c|c|c|}
\hline & Normal 6w & Normal 9w & Slight jaundice & Jaundice & D-penicillamine & $\mathrm{F}_{4,25}$ & $\mathrm{P}$ value \\
\hline Age (weeks) & 6 & 9 & $11-13$ & 11 & 13 & - & $-\mathrm{F}$ \\
\hline Treatment & - & - & - & - & $\begin{array}{c}\text { D-penicillamine } 100 \\
\mathrm{mg} / \mathrm{kg} / \text { day }\end{array}$ & - & - \\
\hline ALT (U/1) & $62.83(\mathrm{SD} 13.7)^{\mathrm{a}}$ & $66.7(\text { SD } 7.7)^{\mathrm{a}}$ & $584.8($ SD 120.4) & $1184(\mathrm{SD} 344.7)^{\mathrm{c}}$ & $45.7(\mathrm{SD} 2.7)^{\mathrm{a}}$ & 56 & $<0.0001$ \\
\hline AST (U/l) & $123.8(\text { SD } 15.3)^{\mathrm{a}}$ & $95.5(\operatorname{SD~} 7.4)^{\mathrm{a}}$ & $479\left(\right.$ SD 144.7) ${ }^{\mathrm{b}}$ & $725.7\left(\right.$ SD 208) ${ }^{\mathrm{c}}$ & $81.8(\text { SD } 2.4)^{\mathrm{a}}$ & 38.8 & $<0.0001$ \\
\hline T-bilirubin $(\mu \mathrm{mol} / \mathrm{l})$ & $2.1(\mathrm{SD} 1.8)^{\mathrm{a}}$ & $1.9(\mathrm{SD} 0.8)^{\mathrm{a}}$ & $107(\mathrm{SD} 64.7)^{\mathrm{b}}$ & $369.7(\mathrm{SD} 228)^{\mathrm{b}}$ & $2.3(\mathrm{SD} 0.6)^{\mathrm{a}}$ & 13.5 & $<0.0001$ \\
\hline $\begin{array}{l}\text { Urinary 8-IsoPGF2 } \alpha \\
\text { (ng/24h) }\end{array}$ & $7.8(\operatorname{SD} 4.4)^{\mathrm{a}}$ & $14.7(\mathrm{SD} 14)^{\mathrm{a}, \mathrm{b}}$ & $30.5(\operatorname{SD~} 10.4)^{\mathrm{b}}$ & $51(\operatorname{SD~21.3})^{\mathrm{c}}$ & $6.4(\mathrm{SD} 1.8)^{\mathrm{a}}$ & & \\
\hline Liver histology & Normal & $\begin{array}{c}\text { Normal } \\
\text { architecture, } \\
\text { Slight hydropic } \\
\text { change. }\end{array}$ & $\begin{array}{c}\text { Abnormal. Conserved } \\
\text { liver architecture; } \\
\text { choleostasis; presence } \\
\text { of micronecrosis and } \\
\text { apoptosis; inflammatory } \\
\text { infiltrates. }\end{array}$ & $\begin{array}{l}\text { Abnomal. Necrosis, } \\
\text { apoptosis, } \\
\text { inflammation, } \\
\text { choleostasis, nuclear } \\
\text { polymorphism, fat } \\
\text { droplets. }\end{array}$ & $\begin{array}{c}\text { Normal. Slight hydropic } \\
\text { change. }\end{array}$ & - & - \\
\hline
\end{tabular}


Table 2. Differential genes classified in GO: Protein Metabolism.

$\mathbf{a}$ is statically differently from $\mathbf{b}$ and $\mathbf{c}$ as determined by ANOVA and the Bonferroni post-hoc test.

\begin{tabular}{|c|c|c|c|c|c|c|c|c|c|}
\hline \multirow[t]{2}{*}{ Description } & \multirow[t]{2}{*}{ Symbol } & \multirow[t]{2}{*}{ Oligo_id } & \multirow[t]{2}{*}{ ENSEMBLE Gene_id } & \multirow[t]{2}{*}{ Genbank } & \multicolumn{4}{|c|}{ Ratio } & \multirow[t]{2}{*}{ p value } \\
\hline & & & & & Normal 6w & Normal 9w & $\begin{array}{c}\text { Slight } \\
\text { jaundice }\end{array}$ & Jaundice & \\
\hline Cathepsin D precursor (EC 3.4.23.5) & Ctsd & Rn30018601 & ENSRNOG00000020206 & NM_134334 & $1.14^{\mathrm{a}}$ & $1.09^{\mathrm{a}}$ & $1.86^{\mathrm{a}, \mathrm{b}}$ & $2.44^{\mathrm{b}}$ & 0.0207 \\
\hline Glycine N-methyltransferase (EC & Gnmt & Rn30014947 & ENSRNOG00000016349 & X06150 & $0.73^{\mathrm{a}}$ & $0.85^{\mathrm{a}, \mathrm{b}}$ & $0.55^{\mathrm{b}}$ & $0.41^{\mathrm{b}}$ & 0.0050 \\
\hline C-reactive protein precursor & Crp & R002545_01 & ENSRNOG00000000053 & DW387982 & $0.68^{\mathrm{a}}$ & $0.89^{\mathrm{a}, \mathrm{b}}$ & $0.45^{\mathrm{b}}$ & $0.35^{\mathrm{b}}$ & 0.0344 \\
\hline $\begin{array}{l}\text { H-2 class II histocompatibility } \\
\text { antigen, gamma chain }\end{array}$ & $\mathrm{Cd} 74$ & Rn30017236 & ENSRNOG00000018735 & CB576583 & $1.06^{\mathrm{a}}$ & $1.15^{\mathrm{a}}$ & $1.73^{\mathrm{b}}$ & $2.36^{\mathrm{c}}$ & 0.0125 \\
\hline $\begin{array}{l}\text { Meprin A alpha-subunit precursor } \\
\text { (EC 3.4.24.18) }\end{array}$ & Mep1a & R004430_01 & ENSRNOG00000011022 & ВC081834 & $0.97^{\mathrm{a}}$ & $0.95^{\mathrm{a}}$ & $0.61^{\mathrm{b}}$ & $0.92^{\mathrm{a}}$ & 0.0351 \\
\hline $\begin{array}{l}\text { proteasome } 26 \mathrm{~S} \text { non-ATPase subunit } \\
12\end{array}$ & Psmd 12 & Rn30002776 & ENSRNOG00000003117 & ВC083758 & $1.10^{\mathrm{a}, \mathrm{b}}$ & $1.01^{\mathrm{a}}$ & $1.05^{\mathrm{a}, \mathrm{b}}$ & $1.48^{\mathrm{b}}$ & 0.0160 \\
\hline Calpain small subunit 1 (CSS1) & Capns1 & Rn30001369 & ENSRNOG00000001503 & ВC098068 & $0.94^{\mathrm{a}, \mathrm{b}}$ & $0.98^{\mathrm{a}}$ & $1.11^{\mathrm{a}, \mathrm{b}}$ & $1.39^{\mathrm{b}}$ & 0.0408 \\
\hline $\begin{array}{l}\text { Serum amyloid P-component } \\
\text { precursor (SAP) }\end{array}$ & Apcs & R000224_01 & ENSRNOG00000009086 & X55761 & $1.01^{\mathrm{a}}$ & $0.84^{\mathrm{a}, \mathrm{b}}$ & $0.41^{\mathrm{b}}$ & $0.54^{\mathrm{a}, \mathrm{b}}$ & 0.0071 \\
\hline $\begin{array}{l}\text { Complement C1q subcomponent } \\
\text { subunit A precursor }\end{array}$ & C1qa & Rn30011801 & ENSRNOG00000012807 & ВC086605 & $1.00^{\mathrm{a}}$ & $0.95^{\mathrm{a}}$ & $1.67^{\mathrm{a}, \mathrm{b}}$ & $1.91^{\mathrm{b}}$ & 0.0439 \\
\hline $\begin{array}{l}\text { TGFB inducible early growth } \\
\text { response } 3 \text { (predicted) }\end{array}$ & Gna14 & Rn30013625 & ENSRNOG00000014840 & ВС090316 & $0.90^{\mathrm{a}}$ & $0.96^{\mathrm{a}}$ & $1.24^{\mathrm{b}}$ & $0.94^{\mathrm{a}}$ & 0.0465 \\
\hline Kit ligand precursor (C-kit ligand) & Kitl & R003524_01 & ENSRNOG00000005386 & NM_021843 & $1.09^{\mathrm{a}}$ & $0.96^{\mathrm{a}}$ & $0.90^{\mathrm{a}}$ & $1.46^{\mathrm{b}}$ & 0.0406 \\
\hline Legumain precursor (EC 3.4.22.34) & Lgmn & Rn30006415 & ENSRNOG00000007089 & ВС087708 & $1.05^{\mathrm{a}, \mathrm{b}}$ & $0.93^{\mathrm{a}, \mathrm{b}}$ & $1.36^{\mathrm{a}}$ & $1.57^{\mathrm{b}}$ & 0.0169 \\
\hline $\begin{array}{l}\text { Ubiquitin-conjugating enzyme E2 B } \\
\text { (EC 6.3.2.19) }\end{array}$ & UBC2_HUMAN & Rn30004545 & ENSRNOG00000005064 & AF144083 & $1.01^{\mathrm{a}, \mathrm{b}}$ & $0.99^{\mathrm{a}, \mathrm{b}}$ & $1.17^{\mathrm{a}}$ & $1.52^{\mathrm{b}}$ & 0.019 \\
\hline $\begin{array}{l}\text { Proteasome subunit beta type } 8 \\
\text { precursor (EC 3.4.25.1) }\end{array}$ & Psmb8 & R004525_01 & ENSRNOG00000000456 & NM_080767 & $1.11^{\mathrm{a}}$ & $1.07^{\mathrm{a}}$ & $1.16^{\mathrm{a}}$ & $1.27^{\mathrm{b}}$ & 0.0317 \\
\hline $\begin{array}{l}\text { Proteasome subunit alpha type } 6 \text { (EC } \\
3.4 .25 .1 \text { ) }\end{array}$ & Psma6 & Rn30006440 & ENSRNOG00000007114 & NM_017283 & $1.10^{\mathrm{a}}$ & $1.01^{\mathrm{a}}$ & $1.16^{\mathrm{a}, \mathrm{b}}$ & $1.44^{\mathrm{b}}$ & 0.0132 \\
\hline $\begin{array}{l}\text { Proteasome subunit beta type } 5 \\
\text { precursor (EC 3.4.25.1) }\end{array}$ & Psmb5 & Rn30012312 & ENSRNOG00000013386 & XM_341314 & $0.93^{\mathrm{a}}$ & $1.05^{\mathrm{a}}$ & $1.15^{\mathrm{a}, \mathrm{b}}$ & $1.43^{\mathrm{b}}$ & 0.0213 \\
\hline $\begin{array}{l}\text { proteasome } 26 \mathrm{~S} \text {, non-ATPase } \\
\text { regulatory subunit } 6\end{array}$ & Psmd6 & Rn30006048 & ENSRNOG00000006751 & ВC059159 & $1.03^{\mathrm{a}}$ & $1.03^{\mathrm{a}}$ & $0.89^{\mathrm{a}}$ & $1.60^{\mathrm{b}}$ & 0.0306 \\
\hline Aminopeptidase B (EC 3.4.11.6) & Rnpep & R002043_01 & ENSRNOG00000006720 & AY724503 & $0.86^{\mathrm{a}}$ & $0.95^{\mathrm{a}}$ & $0.62^{\mathrm{b}}$ & $1.11^{\mathrm{a}}$ & 0.0465 \\
\hline
\end{tabular}


Table 3. Differential genes classified in GO: Nucleobase, Nucleoside, Nucleotide and Nucleic acid Metabolism $\mathbf{a}$ is statically differently from $\mathbf{b}$ and $\mathbf{c}$ as determined by ANOVA and the Bonferroni post-hoc test.

\begin{tabular}{|c|c|c|c|c|c|c|c|c|c|}
\hline \multirow[t]{2}{*}{ Description } & \multirow[t]{2}{*}{ Symbol } & \multirow[t]{2}{*}{ Oligo_id } & \multirow[t]{2}{*}{ ENSEMBLE Gene_id } & \multirow[t]{2}{*}{ Genbank } & \multicolumn{4}{|c|}{ Ratio } & \multirow[t]{2}{*}{ p value } \\
\hline & & & & & Normal 6w & Normal 9w & Slight jaundice & Jaundice & \\
\hline Uricase (EC 1.7.3.3) & Uox & Rn30014939 & ENSRNOG00000016339 & M24396 & $0.69^{\mathrm{a}}$ & $1.04^{\mathrm{a}, \mathrm{b}}$ & $0.57^{b}$ & $0.50^{\mathrm{b}}$ & .0234 \\
\hline $\begin{array}{l}\text { Growth arrest and DNA-damage-inducible } \\
\text { protein GADD45 alpha }\end{array}$ & Gadd45a & R001492_01 & ENSRNOG00000005615 & CO396252 & $1.00^{\mathrm{a}}$ & $0.94^{\mathrm{a}}$ & $1.06^{\mathrm{a}, \mathrm{b}}$ & $1.49^{\mathrm{b}}$ & 0.0055 \\
\hline $\begin{array}{l}\text { Signal transducer and activator of } \\
\text { transcription } 3\end{array}$ & Sta3 & Rn30018174 & ENSRNOG00000019742 & NM_012747 & $0.84^{\mathrm{a}}$ & $0.86^{\mathrm{a}}$ & $1.56^{\mathrm{b}}$ & $1.72^{\mathrm{b}}$ & 0.0498 \\
\hline Dynamin-2 (EC 3.6.5.5) & Dnm2 & Rn30006927 & ENSRNOG00000007649 & L25605 & $1.03^{\mathrm{a}}$ & $1.06^{\mathrm{a}}$ & $1.03^{\mathrm{a}}$ & $1.58^{\mathrm{b}}$ & 0.0151 \\
\hline $\begin{array}{l}\text { Runt-related transcription factor } 1 \text {, Acute } \\
\text { myeloid leukemia } 1 \text { protein }\end{array}$ & Runx1 & Rn30001533 & ENSRNOG00000001704 & L35271 & $0.93^{\mathrm{a}}$ & $1.05^{\mathrm{a}}$ & $1.27^{\mathrm{b}}$ & $1.23^{\mathrm{b}}$ & 0.0280 \\
\hline $\begin{array}{l}\text { Cellular nucleic acid binding protein, Zinc } \\
\text { finger protein } 9\end{array}$ & Cnbp1 & R000749_01 & ENSRNOG00000010239 & CB743905 & $1.06^{\mathrm{a}, \mathrm{b}}$ & $1.09^{\mathrm{a}}$ & $1.07^{\mathrm{a}, \mathrm{b}}$ & $1.45^{\mathrm{a}, \mathrm{b}}$ & 0.0298 \\
\hline DNA-repair protein XRCC1 & Xrcc1 & Rn30018333 & ENSRNOG00000019915 & AF290895 & $1.02^{\mathrm{a}, \mathrm{b}}$ & $0.98^{\mathrm{a}}$ & $1.22^{\mathrm{a}, \mathrm{b}}$ & $1.54^{\mathrm{a}, \mathrm{b}}$ & 0.0338 \\
\hline
\end{tabular}




\section{FIGURE 1}

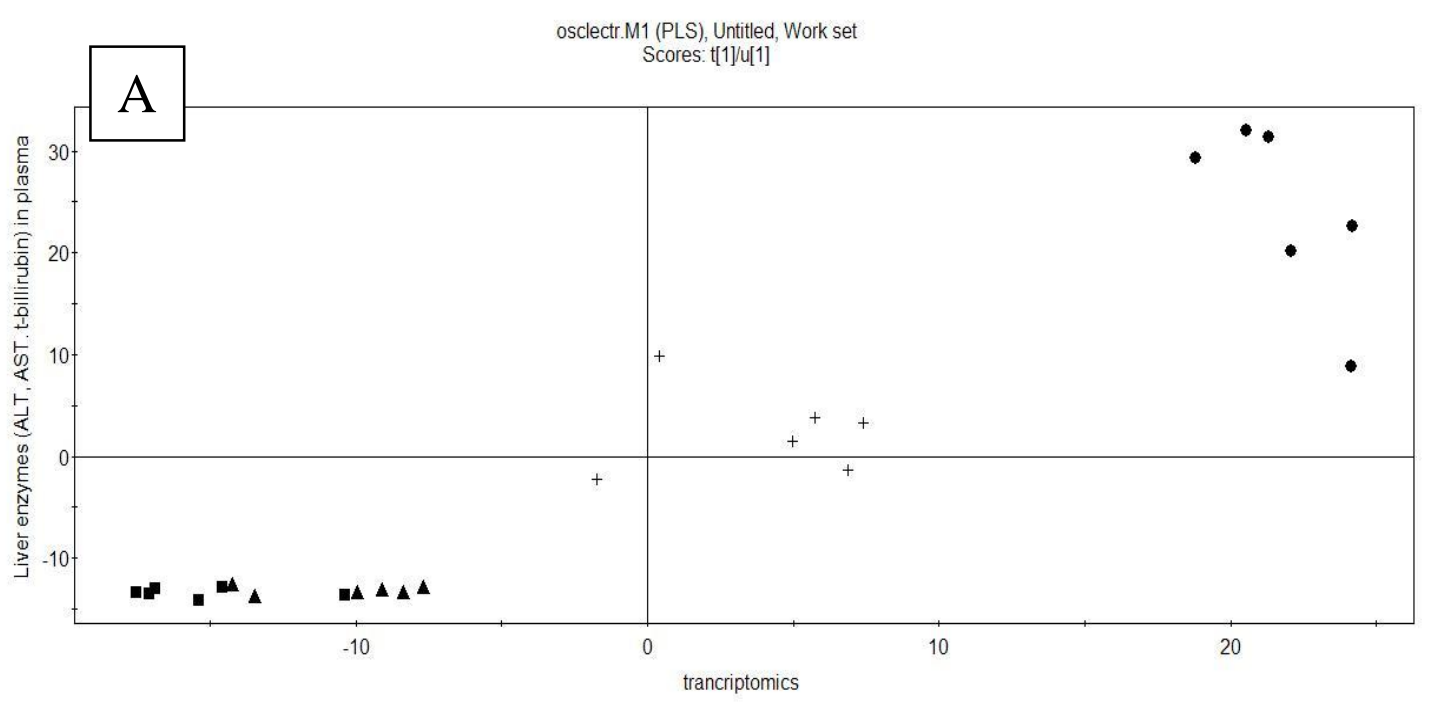

Simca-P 8.0 by Umetrics AB 2007-06-06 13:40

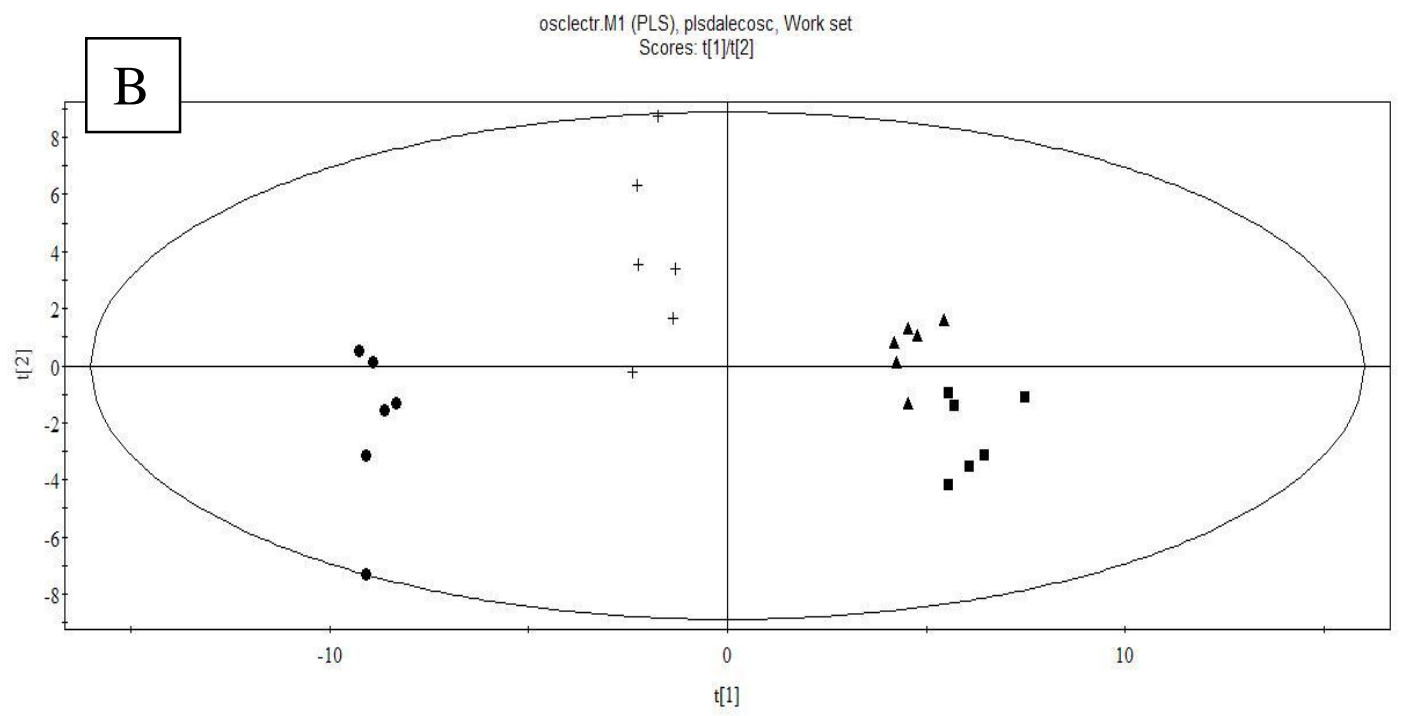

E11ipse: Hotelling I2 $(0.05)$
Simca-P 8 . by Umetrics AB 2007-05-14 22:30 


\section{FIGURE 2}

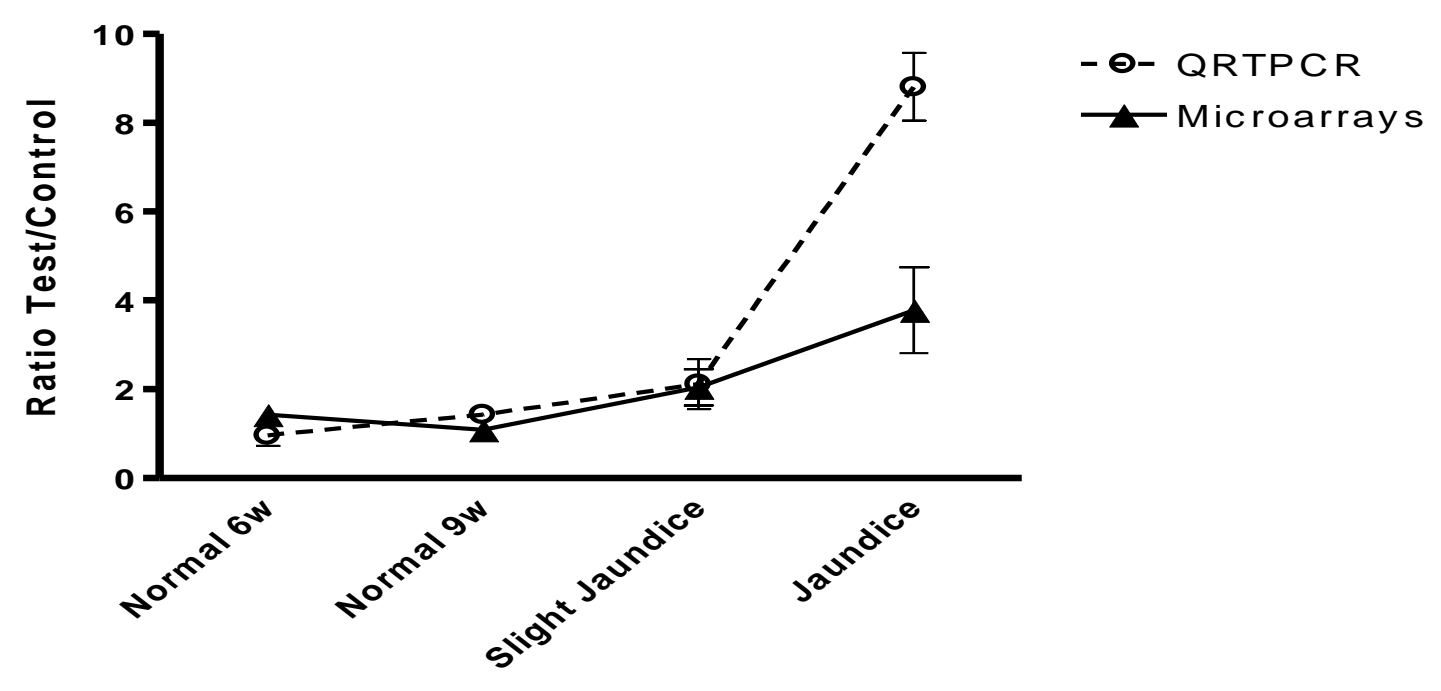




\section{FIGURE 3}

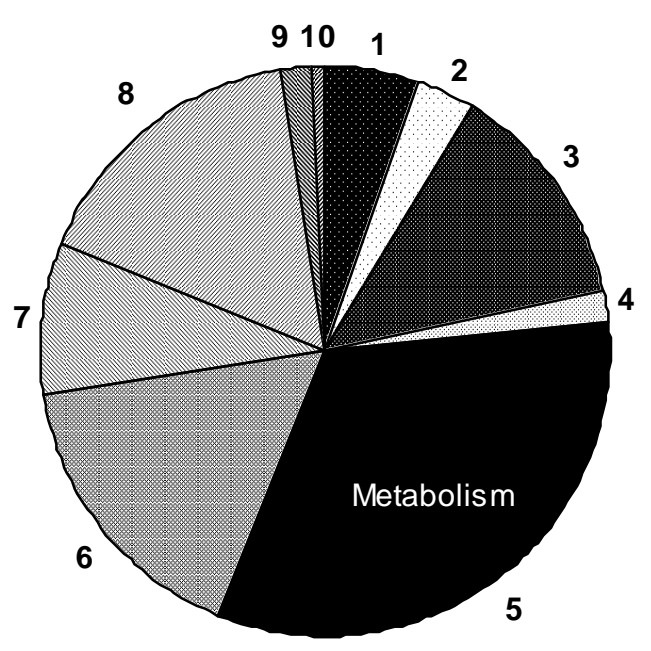

\section{G.O. Biological Process (GO: 0008150): 59, 100 \%}

1. Death (GO: 0016265): 6, 5.2\%

2. Homeostasis (GO: 0019725): 4, 3.5\%

3. Localization (GO: 0051179): $15,13.0 \%$

4. Locomotion (GO: 0040011): $2,1.7 \%$

5. Metabolism (GO: 0044237): 38, 33.0\%

6. Organismal physiological process (GO: 0032501): 19, 16.5\%

7. Physiological response to stimulus (GO: 0050896): 10, 8.7\%

8. Regulation of physiological process (GO: 0050794): 19, 16.5\%

9. Reproductive physiological process (GO: 0048610): 2, 1.7\%

10. Ritmic process (GO: 0048511): 1, 0.9\% 
FIGURE 4

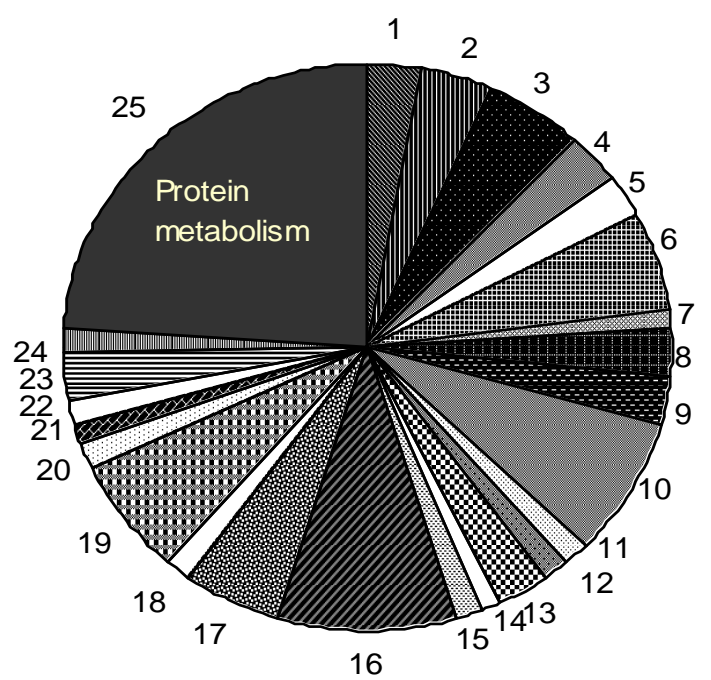

G.O. Metabolism (GO: 0044237): 38, $100 \%$

1. Cellular biosynthesis (GO: 0044249): $2,2.7 \%$

2. Lipid biosynthesis (GO: 008610): 2, $4.0 \%$

3. Cellular catabolism (GO: 0044248): 4, 5.3\%

4. Lipid catabolism (GO: 0016042): 2, 2.7\%

5. Macromolecule catabolism (GO: 009057): 2, 2.7\%

6. Alcohol metabolism (GO: 006066): 4, 5.3\%

7. Amine metabolism (GO: 0009308): 1, 1.3\%

8. Amino acid and derivate metabolism (GO: 0006519): 2, 2.7\%

9. Aromatic compound metabolism (GO: 0006725): 2, 2.7\%

10. Cellular lipid metabolism (GO: 0044255): 6, 8.0\%

11. Cofactor metabolism (GO: 0051186): $1,1.3 \%$

12. Generation of precursor metabolites and energy (GO: 0043467): $1,1.3 \%$

13. Heterocycle metabolism (GO: 0046483): 2, $2.7 \%$

14. Hormone metabolism (GO: 0042455): $1,1.3 \%$

15. Neurotransmiter metabolism (GO: 0042133): 1, 1.3\%

16. Nucleobase, nucleoside, nucleotide and nucleic acid metabolism (GO: 0006139): 7, 9.3\%

17. Organic acid metabolism (GO: 0006082): $4,5.3 \%$

18. Phosphorus metabolism (GO: 0006793): 1, 1.3\%

19. Regulation of cellular metabolism (GO: 0031323): 5, 6.7\%

20. Sulfur metabolism (GO: 0006790): $1,1.3 \%$

21. Vitamin metabolism (GO: 0006766): 1, 1.3\%

22. Xenobiotic metabolism (GO: 0006805): 1, 1.3\%

23. Carbohydrate metabolism (GO: 0005975): 2, 2.7\%

24. Macromolecule catabolism (GO: 0044265): 2, $2.7 \%$

25. Protein metabolism (GO: 0044260): 18, $2 \%$ 
FIGURE 5

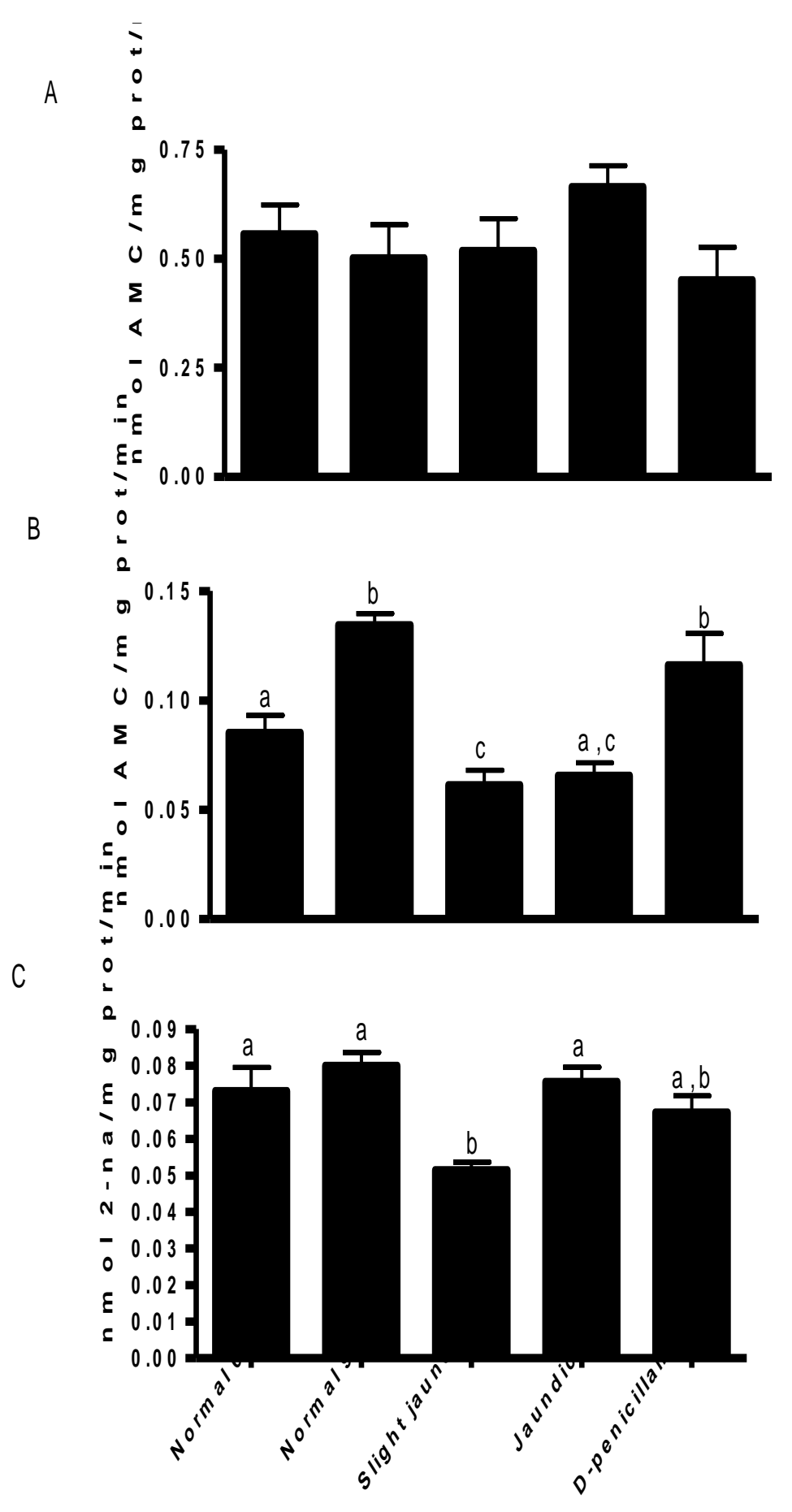




\section{FIGURE 6}

A

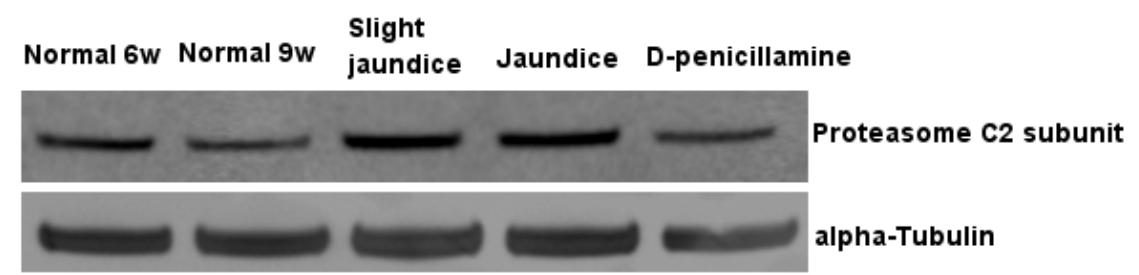

B

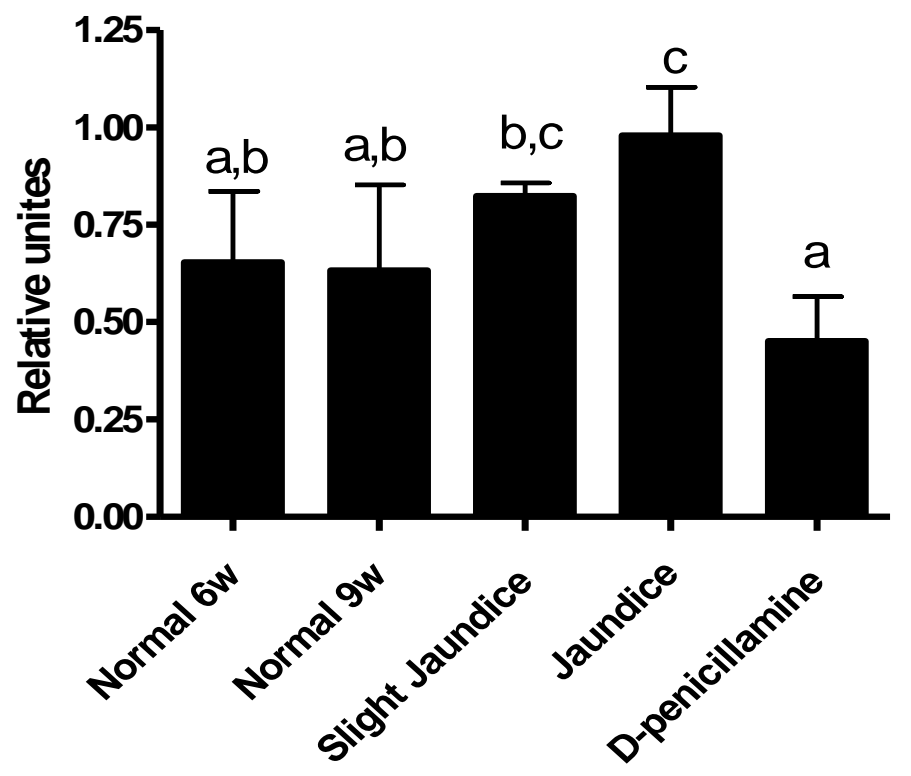

